\title{
Os saberes docentes nos cursos de licenciatura a distância em ciências naturais e matemática nos institutos federais do Brasil
}

\author{
Teaching knowledge in distance education degree courses \\ in natural sciences and mathematics \\ at the federal institutes in Brazil
}

\author{
Roberta Pasqualli ${ }^{1}$ • Marie Jane Soares Carvalho ${ }^{2}$
}

\begin{abstract}
Resumo: O texto analisa os saberes docentes mobilizados pelos professores dos cursos de Licenciatura em Ciências Naturais e Matemática na modalidade de educação a distância (EAD) nos Institutos Federais (IF) de Educação, Ciência e Tecnologia. O método de investigação, fenomenológico, estruturou-se em três etapas. Na primeira etapa foram localizados, entre todos os IF do Brasil, os que possuíam cursos de Licenciatura em Ciências Naturais e Matemática na modalidade de EAD. Na segunda etapa, foram analisados seus ordenamentos institucionais. E, na terceira etapa, por meio da análise ideográfica e nomotética, buscou-se identificar elementos para elucidar os saberes docentes no contexto das licenciaturas nos IF. Considerou-se que os saberes oriundos da profissionalização docente são frutos de formação inicial e continuada, consciente, ética, crítica e pautada em trajetórias que reflitam continuamente sobre o processo de formação, sobre o espaço de trabalho e sobre o mundo desejado para si e para os outros.
\end{abstract}

Palavras-chave: Formação de professores. Ensino superior. Educação a distância. Ensino de ciências naturais. Ensino de matemática.

\begin{abstract}
This paper analyzes the teaching knowledge used by professors of Natural Sciences and Mathematics distance education degree undergraduate programs at Federal Institutes (FI) of Education, Science and Technology. The method of investigation, phenomenologically, was structured in three phases. In the first step, there was the identification, among all the Institutes in Brazil, among those that offer the Natural Sciences and Mathematics in the distance education mode. The second step involved the analysis and institutional framework of the Institutes. And in the last stage, through the ideographic and nomothetic analyses, there was the identification of elements to enlighten the teaching knowledge in the context of the degree courses at FI. It was considered that the teaching knowledge coming from the teaching profession is a result of an initial and consciously continued formation, which is also ethical and critical and which is guided by trajectories that continuously reflect upon the process of teaching formation, upon the work space and upon the desired world for the professor and for others.
\end{abstract}

Keywords: Teacher knowledge. Teachers Formation. Distance Learning. Natural Science. Mathematics.

\footnotetext{
${ }^{1}$ Instituto Federal de Educação, Ciência e Tecnologia de Santa Catarina (IFSC), Departamento de Desenvolvimento de Ensino, Chapecó, SC, Brasil. E-mail: <roberta.pasqualli@ifsc.edu.br>

${ }^{2}$ Universidade Federal do Rio Grande do Sul (UFRGS), Faculdade de Educação, Departamento de Ensino e Currículo, Programa de Pós-Graduação em Informática na Educação, Porto Alegre, RS, Brasil.
} 


\section{Considerações iniciais}

Este texto discorre sobre a problemática dos saberes docentes mobilizados pelos professores dos cursos de Licenciatura em Ciências Naturais e Matemática, desenvolvidos na modalidade de Educação a Distância (EAD), nos Institutos Federais de Educação, Ciência e Tecnologia (IF), e como tais saberes norteiam os alcances e os limites que tencionam o trabalho docente.

Partiu-se do princípio de que investigar os saberes docentes necessários aos professores dos cursos de Licenciatura em Ciências Naturais e Matemática a distância dos IF, por meio das relações existentes entre suas trajetórias formativas e práticas, significa reafirmar a necessidade da retomada da tradição cultural, marcada por processos de ensino-aprendizagem inovadores, em contraposição aos modelos clássicos de formação de professores. Significa que no espaço de contradições que é o espaço universitário "[...] o que um professor sabe depende também daquilo que ele não sabe, daquilo que se supõe que ele não saiba, daquilo que os outros sabem em seu lugar e em seu nome, dos saberes que os outros lhe opõem ou lhe atribuem" (TARDIF, 2002, p. 13).

Como lócus, para a realização da pesquisa, escolheram-se os IF, estruturas educacionais relativamente novas, criados pela Lei $\mathrm{n}^{\circ} 11.892$, de 29 de dezembro de 2008. De acordo com seu Art. $8^{\circ}$, devem oferecer cursos de Educação Profissional Técnica de Nível Médio, preferencialmente integrados ao Ensino Médio; cursos de Licenciatura, bem como programas especiais de formação pedagógica, com vistas à formação de professores para a Educação Básica, sobretudo nas áreas de Ciências e Matemática; Graduações Tecnológicas, podendo ainda ofertar cursos de Especialização Lato e Stricto Sensu, tendo em vista a Educação Profissional. Ainda no mesmo artigo da Lei $\mathrm{n}^{\circ} 11.892$, pode-se observar o destaque ao percentual de vagas a ser garantido para os cursos de Licenciaturas, vinte por cento $(20 \%)$. Cabe ainda destacar que formar professores de forma diferenciada da corporificada pela Universidade clássica é uma das bandeiras dos documentos oficiais, referenciais norteadores e dos discursos políticos apresentados pela Secretaria de Educação Profissional e Tecnológica (SETEC) do Ministério da Educação (MEC). (BRASIL, 2008).

Para Pacheco (2010, p. 14), no que tange à orientação pedagógica, os IF devem:

[...] recusar o conhecimento exclusivamente enciclopédico, assentandose no pensamento analítico, buscando uma formação profissional mais abrangente e flexível, com menos ênfase na formação para ofícios e mais na compreensão do mundo do trabalho e em uma participação qualitativamente superior neste. Um profissionalizar-se mais amplo, que abra infinitas possibilidades de reinventar-se no mundo e para o mundo, princípios estes válidos inclusive para as engenharias e licenciaturas.

Nessa direção, articular as experiências e os conhecimentos prévios dos estudantes, utilizando-os como elementos para a elaboração de propostas pedagógicas que propiciem a formação do homem e do profissional, é apenas um dos desafios para os quais os IF foram criados. Dessa forma, democratiza-se o acesso ao conhecimento científico, assegurando sua aplicabilidade no mundo do trabalho. Entretanto, essa transformação não é possível sem que haja uma ruptura com o modo tradicional de se fazer educação. 
Cunha (2005) apresenta a ideia de que é necessário romper com o paradigma existente e que esse rompimento gera a inquietude em energia emancipatória.

Entendemos que a inovação requer uma ruptura necessária que permita reconfigurar o conhecimento para além das regularidades propostas pela modernidade. Ela pressupõe, pois, uma ruptura paradigmática e não apenas a inclusão de novidades, inclusive as tecnológicas. Nesse sentido envolve uma mudança na forma de entender o conhecimento. (CUNHA, 2005, p. 12).

Compreende-se, assim, que inovar é incorporar, além de novas tecnologias, novos conhecimentos e novas relações entre esses conhecimentos, novos olhares para um objeto que precisa cada vez mais de um paradigma e uma roupagem adequada ao contexto no qual está inserido. E é buscando a inovação necessária ao mundo contemporâneo que a proposta dos IF se apresenta. Considera-se que as instituições de ensino precisam estar cada vez mais próximas da comunidade acadêmica e da sociedade civil, presentes na vida do maior número possível de pessoas, transformando-se no espaço de referência para a formação de sujeitos críticos, que produzem conhecimento e não apenas o reproduzem.

Imersos nos mesmos dilemas das Universidades clássicas, acrescidos das novas exigências a eles impostos, os IF, com pouca experiência na oferta de cursos de formação de professores, têm oferecido cursos de Licenciatura na modalidade de EAD. A EAD, por sua vez, vive mergulhada em desafios: um deles é o de construir uma identidade própria, desvinculada da reprodução de métodos da educação presencial. Para isso, precisa elaborar modelos próprios capazes de qualificá-la e consolidá-la como modalidade educacional séria, a fim de contribuir com a formação de sujeitos críticos e capazes de lidar com o mundo do trabalho e com as circunstâncias do mundo cotidiano.

É importante destacar que a discussão acerca da formação de professores, por meio da modalidade de EAD, vem, nos últimos anos, sendo atentamente assumida e/ou forjada pelas políticas públicas e pelas necessidades e contradições que cercam a Universidade e, neste caso, especialmente os IF. Por isso da singularidade de se compreender a problemática dos saberes docentes mobilizados pelos professores em cursos de Licenciatura a distância, das áreas de Ciências Naturais e Matemática, dos IF, ou seja, as práticas educativas existentes e possíveis de serem alteradas. Ressalta-se que tal problemática, faz com que se volte o olhar para uma visão de alteridade, defendida por Laplantine (2006, p. 21), como

A experiência da alteridade [...] leva-nos a ver aquilo que nem teríamos conseguido imaginar, dada a nossa dificuldade em fixar nossa atenção no que nos é habitual, familiar, cotidiano, e que consideramos 'evidente'. Aos poucos, notamos que o menor de nossos comportamentos (gestos, mímicas, posturas, reações afetivas) não tem realmente nada de 'natural'.

Sabe-se que a EAD pode ser considerada como uma possibilidade real de ampliação da democratização do acesso ao conhecimento científico sistematizado. Por possuir características próprias, ela se apresenta como um processo de inovação da educação formal, já que impõe a necessidade de novas aprendizagens e ensinagens por parte de quem planeja, desenvolve e 
avalia. Implica, inclusive, a construção de uma nova maneira (e novos saberes) de compreender o processo de ensino-aprendizagem.

Cabe aqui, também, a preocupação com a educação superior, especialmente no que tange à qualidade de seus resultados, averiguada por processos avaliativos externos, inerentes ao caráter neoliberal das políticas governamentais. Esses processos também estão refletidos na Lei nº 9394, de dezembro de 1996, a Lei de Diretrizes e Bases da Educação (LDB) (BRASIL, 1996), prescritos pela competitividade, em detrimento da solidariedade, banalizando-a e tornando-a mercadoria.

É nesse contexto que este texto foi elaborado, concebido como uma reflexão, uma revisão, um processo de investigação articulado à realidade atual. Partiu-se do pressuposto de que a produção científica deve se caracterizar como um espaço que busca qualificar a ação docente na educação superior, especialmente na formação de professores na modalidade de EAD, situando-a como possibilidade de superação do fazer tradicional, presente na maioria das aulas universitárias (e na própria EAD), criando, de fato, rupturas com o fazer existente.

\section{Os saberes docentes}

Tardif (2002, p. 36) define saber docente como "um saber plural, formado pelo amálgama, mais ou menos coerente, de saberes oriundos da formação profissional e de saberes disciplinares, curriculares e experienciais." O autor atribui ao saber docente um sentido amplo, que engloba os conhecimentos, as competências, as habilidades (ou aptidões) e as atitudes dos docentes, tudo aquilo que é chamado de saber, de saber-fazer e de saber-ser.

O conceito de saber, em seu sentido amplo, engloba conhecimentos, competências, habilidades e atitudes. Tardif (2002, p. 11) ressalta que:

A finalidade de uma epistemologia da prática profissional é revelar esses saberes, compreender como são integrados concretamente nas tarefas dos profissionais e como estes os incorporam, produzem, utilizam, aplicam e transformam em função dos limites e dos recursos inerentes às suas atividades de trabalho. Ela também visa compreender a natureza desses saberes, assim como o papel que desempenham tanto no processo de trabalho docente quanto em relação à identidade profissional dos professores.

Para Charlot (2000, p. 62) "não é o saber que é prático, mas, sim, o uso dele, em uma relação prática com o mundo”. Essa perspectiva permite deduzir que a prática pode ser também uma forma de saber e, na mesma lógica, pode-se inferir que os saberes práticos dos professores são mobilizados em suas práticas de ensino, com base em sua atuação profissional, durante a construção da professoralidade.

O autor dá como exemplo de relação de identidade com o saber: "uma aula interessante é uma aula na qual se estabelece uma forma específica, uma relação com o mundo, uma relação consigo mesmo e uma relação com o outro" (CHARLOT, 2000, p. 73). Para ele, as raízes dos saberes docentes estão intrinsecamente ligadas com o vivido e com os processos formativos, o que ajudará na reflexão e na prática da atividade docente. 
Pimenta (1999), por sua vez, descreve o surgimento da questão dos saberes docentes como algo intimamente associado aos estudos sobre a identidade da profissão docente. A autora parte do princípio de que a identidade do professor é construída a partir da significação social da profissão; da revisão constante dos significados sociais da profissão; da revisão das tradições, mas não descarta, ao contrário, reafirma que as práticas consagradas, culturalmente, ainda permanecem significativas. Essas práticas resistem a inovações porque ainda estão repletas de saberes válidos às necessidades da realidade. Resultam do confronto entre as teorias e as práticas, da análise sistemática das práticas à luz das teorias existentes, da construção de novas teorias.

Pimenta (1999, p. 20) identifica que os saberes da experiência “[...] são também aqueles os quais os professores produzem no seu cotidiano docente, num processo permanente de reflexão sobre sua prática [...]”. A autora prossegue explicando que:

Constrói-se, também, pelo significado que cada professor, enquanto ator e autor, confere à atividade docente no seu cotidiano a partir de seus valores, de seu modo de situar-se no mundo, de sua história de vida, de suas representações, de seus saberes, de suas angustias e anseios, do sentido que tem em sua vida o ser professor [...] (PIMENTA, 1999, p. 19)

Pimenta (1999) retoma a necessidade de que se considere a autoformação e a reelaboração dos saberes iniciais do professor em permanente confronto com sua prática vivenciada, uma vez que é nesse processo que os professores constituem seus saberes como prática, refletindo na e sobre essa prática.

Já para Nóvoa (2001), os saberes necessários ao professor giram em torno da organização e da compreensão do conhecimento. Como organizador da aprendizagem, o professor precisa compreender a organização do ponto de vista mais amplo, que é a organização da turma ou da sala de aula. Enquanto detentor da compreensão do conhecimento, "não basta deter o conhecimento para saber transmitir a alguém, é preciso compreender o conhecimento, ser capaz de o reorganizar, ser capaz de reelaborar e de transpô-lo em situação didática em sala de aula." (NÓVOA, 2001).

Contreras (2002), referindo-se aos saberes docentes, afirma que várias situações vivenciadas em sala de aula estão repletas de espontaneísmo, não são ações oriundas de reflexões mais apuradas e não há clareza das intencionalidades. Em sua análise, afirma que muitos professores somente desenvolvem saberes oriundos da prática e persistem na utilização desses conhecimentos sem atentar-se ao fato de que somente este saber pode ser insuficiente para dar conta das indeterminações presentes no fazer pedagógico. $\mathrm{O}$ autor destaca que o profissional:

Conforme sua prática fica estável ou restritiva, seu conhecimento na prática se torna mais tácito e espontâneo. É esse conhecimento profissional que lhe permite confiar em sua especialização. Porém, à medida que os casos reflitam diferenças, ou lhe criem dúvidas [...]. Seu conhecimento profissional acumulado e tácito se mostra insuficiente para dar conta deste caso e são outros os recursos que irá utilizar. Necessita refletir, confrontar seu conhecimento prático com a situação para a qual o repertório disponível 
de casos não lhe proporciona uma resposta satisfatória. (CONTRERAS, 2002, p. 107-108)

Freire (1996), em seu livro "Pedagogia da Autonomia", tece reflexões sobre os saberes necessários à prática educativa, defendendo princípios da dialogicidade e politicidade, ou seja, da conscientização e formação política dos sujeitos, a partir de nove saberes fundamentais à condução do processo ensino-aprendizagem. O primeiro saber refere-se à atividade de ensinar como ação que exige rigorosidade metódica. Nessa perspectiva, a ação do professor é criativa, instigante, inquieta, rigorosamente curiosa, humilde e persistente. $O$ ensino com pesquisa ganha destaque no segundo saber, já que, para Freire (1996), não há ensino que parta apenas do senso comum. Assim, o professor necessita do conhecimento científico para organizar o ensino e o veículo dessa organização é a pesquisa. O terceiro saber diz respeito ao desenvolvimento do ensino a partir do respeito aos saberes dos estudantes: o professor deve valorizar os saberes dos estudantes. Esses saberes podem ser das classes populares e, por isso, é preciso trabalhar com os estudantes as necessidades comunitárias, ao mesmo tempo em que se sistematizam conhecimentos para que esses alunos possam avançar na construção do conhecimento. Vasconcellos (2002) chama esse movimento de síncrese, análise e síntese, o que significa partir dos conhecimentos do senso comum e propiciar condições para fazer que o estudante avance nas suas construções conceituais. O quarto saber atreve-se a desejar que o processo de ensino desenvolva a criticidade e, para isso, o professor precisa construir condições de aprendizagem para que os estudantes possam aprender a se defender das ideologias existentes na sociedade que manipulam interesses e compreensões. $O$ ensino da estética e ética aparece como o quinto saber e refere-se ao investimento em aprendizados que explorem as subjetividades do mundo e do homem e suas implicações na trajetória pessoal e profissional. O sexto saber exige um ensino que se volta para a educação pelo exemplo. Dessa forma, o professor educa pelo exemplo. Aceitar o novo e rejeitar qualquer tipo de discriminação significa olhar para o novo não apenas com o deslumbramento da novidade, mas como uma possibilidade que não exclui o velho apenas por ser velho, construindo uma prática mais fundamentada e consciente dos implicantes sociais que lhe são inerentes, esse é o sétimo saber. O oitavo saber exige que o professor aprenda a refletir criticamente sobre a prática docente e tal análise é necessária, além de envolver exercício constante e contínuo de ação-reflexão-ação. O nono e último saber exige o aprendizado e o reconhecimento de que o ser humano é um ser social, histórico e cultural.

Uma das tarefas mais importantes da prática educativo-crítica é propiciar as condições em que os educandos em suas relações uns com os outros e todos com o professor ou a professora ensaiam a experiência profunda de assumir-se. Assumir-se como ser social e histórico como ser pensante, comunicante, transformador, criador, realizador de sonhos, capaz de ter raiva porque capaz de amar. Assumir-se como sujeito porque capaz de reconhecer-se como objeto. A assunção de nós mesmo não significa a exclusão dos outros. É a “outredade" do "não eu”, ou do tu, que me faz assumir a radicalidade de meu eu. (FREIRE, 1996, p. 41) 
Tardif (2002), Pimenta (1999), Nóvoa (2001), Contreras (2002) e Freire (1996), de uma maneira ou de outra, destacam que a extensão e o domínio do saber docente abrangem, além do conhecimento específico da área que será ensinada, o saber da ciência da educação e da própria prática docente.

Demarcado o contexto teórico em que este estudo se apresenta, parte-se da compreensão do saber docente, como saber social, que se manifesta nas relações complexas entre os professores e os estudantes. Pois, se os saberes docentes são sociais, os saberes dos estudantes também o são e, logo, exigem dos professores formadores o respeito às construções históricas de cada sujeito. E, por fim, a necessidade de inovar; não inundar a sala de aula de novidades, mas inovar no sentido de romper com o que já não cabe nos espaços de ensino-aprendizagem contemporâneos, carregados de certezas provisórias e de dúvidas permanentes.

\section{O caminho metodológico}

Tendo como foco a interrogação "Que saberes docentes são mobilizados pelos professores dos cursos de Licenciatura em Ciências Naturais e Matemática, desenvolvidos na modalidade de EAD, nos Institutos Federais de Educação, Ciência e Tecnologia?” este texto apresenta resultados de uma investigação que buscou compreender o sentido dos saberes pedagógicos, mobilizados pelos sujeitos onde o trabalho efetiva-se, ou seja, nos cursos de Licenciatura em Ciências Naturais e Matemática, desenvolvidos na modalidade de EAD, nos IF, bem como, almejar a compreensão da pluralidade apresentada pelos sistemas de ensino nesta modalidade de educação.

O lócus da pesquisa foram os sete Institutos Federais de Educação, Ciência e Tecnologia que ofertavam, até março de 2013, os cursos de Licenciatura em Física, Química, Biologia e Matemática na modalidade de EAD. Os sujeitos investigados foram 12 gestores de $\operatorname{EAD}(\mathrm{G})$, 16 professores pesquisadores (PP), 26 professores formadores $(\mathrm{PF})$ e 31 tutores (T). É importante destacar que alguns dos sujeitos investigados exerciam mais de uma função no momento da pesquisa.

Sobre os sujeitos investigados, destaca-se:

- quanto ao gênero: (a) 54\% de mulheres; (b) 46\% de homens;

- quanto ao tempo de trabalho na educação: (a) 24\% até 5 anos; (b) $22 \%$ até 10 anos; (c) 19\% até 15 anos; (d) 19\% até 20 anos; (e) 16\% mais de 20 anos;

- quanto à formação acadêmica: (a) $9 \%$ graduados; (b) 30\% especialistas; (c) $52 \%$ mestres; (e) $9 \%$ doutores;

- quanto à formação acadêmica específica: (a) 33\% Licenciatura em Matemática; (b) 20\% Licenciatura em Química; (c) 16\% Licenciatura em Ciências Biológicas; (d) 14\% Licenciatura em Física; (e) 17\% outras formações (Licenciaturas, Bacharelados e Cursos Superiores de Tecnologia); tecnólogos.

- quanto à formação para a docência: (a) 91\% de licenciados; (b) 9\% de bacharéis e

Ao procurar possibilidades que abarcassem o desenvolvimento da pesquisa realizada, optou-se pelas abordagens qualitativa e fenomenológica. Uma vez que a primeira está relacionada “à capacidade de possibilitar a compreensão do significado e a descrição densa dos fenômenos 
estudados em seu contexto e não a sua expressividade numérica.” (GOLDENBERG, 1997, p. 50). Enquanto que a segunda

[...] não traz consigo a imposição de uma verdade teórica ou ideológica preestabelecida, mas trabalha com o real vivido, buscando a compreensão disso que somos e que fazemos - cada um de nós e todos em conjunto. Buscando o sentido e o significado mundanos das teorias e das ideologias e das expressões culturais e históricas. (BICUDO, 1999, p. 13)

A investigação foi estruturada em três etapas. A primeira, de enfoque quantitativo, identificou, entre todos os IF do Brasil, os que possuíam, até março de 2013, cursos de Licenciatura em Ciências Naturais e Matemática, na modalidade de EAD, ofertados pela UAB ou pela própria instituição.

Em um segundo momento, foram analisados os ordenamentos institucionais e Projeto Político Institucional (PPI), Projeto de Desenvolvimento Institucional (PDI) dos sete IF investigados. O objetivo foi buscar informações sobre as políticas de EAD, incluindo, especialmente, a questão da formação de professores nessa modalidade. Também foram analisados onze Projetos Pedagógicos de Curso (PPC) de Matemática, Física, Química e Biologia, em busca de indicadores de processos inovadores de formação de professores para a modalidade.

A terceira etapa da pesquisa foi realizada em dois momentos que consistiram na análise ideográfica e na análise nomotética dos dados. Buscou-se identificar, direta e indiretamente, elementos que pudessem indicar os saberes docentes no contexto das licenciaturas nos IF. No que se refere à análise ideográfica, os resultados foram produzidos a partir das falas de professores formadores, professores pesquisadores, tutores e gestores, dos cursos de Ciências Naturais e Matemática, oferecidos na modalidade de EAD, pelos IF do país. Os depoimentos foram individuais, sem a interferência de terceiros, baseados em questionamentos previamente elaborados. Entretanto, elementos não existentes nos questionamentos diretos foram apresentados sem que houvesse interferência do pesquisador. Foi o momento de se olhar as frestas, aquilo que se anuncia como saber sem necessariamente perguntar. $\mathrm{Na}$ análise nomotética, as falas dos sujeitos foram encaminhadas em direção às generalidades, ou seja, de características básicas compreendidas nas formas de manifestação do fenômeno, passíveis de interpretação. a seguir.

É esse movimento da pesquisa e seus desdobramentos analíticos que serão explorados

\section{Do método aos resultados}

Das falas dos sujeitos investigados tomadas, refletidas e esclarecidas, na dimensão científica, foi possível seguir para uma síntese de compreensão do fenômeno investigado, por meio das análises ideográfica e nomotética.

$\mathrm{Na}$ análise ideográfica, as falas dos sujeitos da pesquisa foram transcritas na íntegra. Ao ouvir as falas durante a transcrição, pôde-se perceber as temáticas que remetem à ideia central da pesquisa, e essas ideias centrais foram nomeadas como episódios ideográficos. Ao todo, foram apontados sete episódios ideográficos, descritos a seguir: 
- o que é importante para ser professor e o que fez falta na formação acadêmica;

- saberes fundamentais para os professores que atuam nos cursos de formação de professores na modalidade de EAD;

- tensões entre os cursos presenciais e na modalidade de EAD;

- currículo dos cursos na modalidade de EAD;

- projeto político dos cursos de EAD;

- práticas inovadoras na EAD;

- outros elementos apresentados nas conversas.

Desses sete episódios ideográficos, destacaram-se quarenta e duas ideias nucleares que trouxeram elementos de análise para a pesquisa. No primeiro episódio ideográfico, o que é importante para ser professor e o que fez falta na formação acadêmica, emergiram, entre outros, as questões da formação didático-pedagógica para o exercício da docência, dos conhecimentos da área de formação específica, da experiência adquirida através da observação de professores mais experientes e, embora discutível, a vocação. As falas, na sequência, representam parte dos sentimentos expostos pelos sujeitos investigados:

[...] considero a formação pedagógica, o conhecimento do fazer docente, das metodologias e estratégias de ensino, independente da área de atuação. Minha primeira experiência docente aconteceu logo ao finalizar o Mestrado, no curso de Pedagogia, com a disciplina de Didática dos Meios I e II. Foi um desafio, primeiro pelo conteúdo, ministrar disciplina raiz do curso de Pedagogia. Segundo, por minha falta de vivência prática. Tive que desenvolver intensos planejamentos que contribuíram para eu alcançar confiança e desenvolver o trabalho. Em algum momento era necessário comescar e, comecei ali, foi mágico. No que tange ao conteúdo aprendido em meu curso de formação inicial, este pouco interferiu na minha prática inicialmente, pois tive que estudar muito para conseguir planejar as disciplinas. A observação da prática dos meus professores, o currículo oculto, aquele que não se objetiva ensinar, mas ensina-se pela vivência concomitante, ajudou-me demais em resgatar meus saberes e colocá-los em prática. Talvez o que mais tenha feito falta foi a experiência, mas, esta, só o tempo [...]. [T44]

Penso que é necessário o conhecimento técnico e científico, a experiência nas relações interpessoais, o uso adequado nas novas tecnologias, a liberdade e autonomia de experimentar novas práticas pedagógicas. [T45]

O mais importante é a visão de mundo e a consciência do sobre a função social do docente. A partir disso, épossivel traçar estratégias de ensino coerentes com essa visão e as concepcõoes subjacentes. O conbecimento técnico científico permeia todo o processo de ensino, pois sem esse conbecimento não teria sentido ensinar. [PF15, PP15, T15]

No meu caso, a vocação docente veio muito cedo, no Ensino Médio já dava aulas particulares para colegas de turma. Depois, já no Superior ministrava aulas em escolas de Informática e com 15 anos já dava aulas particulares. [PF51] 
Embora creia ser possivel se formar um professor, desde que haja empenho e dedicação sincera para isso, porparte do futuro professor, considero importante um aspecto geralmente pouco considerado: o dom de ser professor. [PF14, PP14, T14]

O segundo episódio ideográfico apresentou a discussão sobre os saberes fundamentais para os professores que atuam nos cursos de formação de professores na modalidade de EAD e nele pôde-se observar como principais aspectos, destacados pelos sujeitos investigados, a necessidade de conhecer a modalidade EAD, de ter domínio sobre as TICs, de conhecer a realidade acerca dos estudantes, sendo generoso, sem deixar de lado o rigor acadêmico necessário e contar com experiência. Na sequência, apresentam-se algumas falas acerca do episódio:

[...] entendo ser necessário alguns diferenciais para um professor que atua na $\mathrm{E} A D$ como saber elaborar um material que atenda as expectativas do aluno quanto à disciplina, administrar o fato de o aluno em EAD não estar presente corporeamente, manter contínu contato com os alunos e canais de comunicação, pois o sentimento de distância entre o professor e o aluno é um fato em EAD. [PF10, PP10, T10]

É importante lembrar que a $E A D$ se desprende um pouco das imagens, logo as palavras precisam sem mais cuidadas. Nas expressões que atraiam as atenções e as carências dos educandos. [T20]

[...] além de uma concepsão de homem que deseja-se formar, é necessário acreditar que esta modalidade é uma modalidade possivel de se ensinar e aprender [...] é saber usar dos recursos tecnológicos, das linguagens e meios de alcançar os alunos, prender a atenção deste, sem necessariamente tê-lo sentado em sua frente. [T44]

[...] professor tem que se colocar no lugar do aluno e na maioria isso só acontece quando o professor vai ao polo do aluno, onde ele conbece a realidade do mesmo [...]. [PF1, T1]

O terceiro episódio ideográfico destacou as tensões entre os cursos presenciais e na modalidade de EAD e trouxe à luz questões melindrosas sobre a pesquisa. Essas questões parecem ficar esquecidas e são apresentadas como: problemas metodológicos, desvalorização, fragilidades conceituais e técnicas da EAD à tona. Observam-se, na continuidade, algumas falas:

$O$ aluno do curso tradicional tem contato toda semana com o professor, presta atenção na explicação, resolve os exercícios em sala com o professor, enfim é um contato diário. Já a EAD tem suas peculiaridades, por exemplo, acho um absurdo o material ser preparado por um professor, mas quem dá aula é outro. O professor formador nem tem contato com a turma, nem sabe onde eles têm dificuldade, acho muito mal feito, o mesmo professor que dá aula deveria elaborar provas e tarefas, a apostila até aceito receber de outros professores, mas a prova e as atividades não acho legal, dificulta o aprendizado. Para mim isso tudo é pra pagar bolsas para mais pessoas. [T32] 
Já ouvi de alguns professores que lecionam em Graduação presencial um certo desdém em relação a EAD. Isso, no meu ponto de vista, é falta tanto de informação, quanto de uma política de expansão e marketing positivo nesta modalidade. Na região onde moro muitos jovens desconhecem os cursos ofertados pelo IF 'C' e demais instituiçoes onde a EAD se faz.presente. [T42]

Percebo que a formação inicial não deveria ocorrer a distância, pois provoca um aligeiramento na formação do sujeito, se no presencial há uma formação fragmentada na distância esta situação aumenta. Os alunos apresentam dificuldades, em relação à Matemática é muito complicado tirar dúvidas por fóruns e vídeo-conferências. [T22]

As discussões sobre o currículo do curso na modalidade de EAD aconteceram no quarto episódio ideográfico e nele ficaram claras as fragilidades na elaboração, na forma de condução e no que se refere ao conhecimento dos mesmos por parte dos professores. Por outro lado, também aparecem relatos importantes de experiências curriculares valorosas para a formação efetiva dos professores.

Encontramos muitas divergências, sombreamentos de conteúdos e lacunas no currículo do curso. Isso porque ainda não houve discussão eficiente na construção das ementas, não houve encontros específicos de debate e confronto de ementas entre disciplinas afins, a não ser em algumas disciplinas onde os professores atuam juntos também no ensino presencial. [PF8, PP8]

Não tenho muito conhecimento para falar sobre isso porque leciono no curso de Matemática apenas duas disciplinas porque sou economista. [T32]

O currículo tem sido bastante relevante na distribuição dos conteídos, abordando de maneira eficaz tanto a prática docente, como a prática profissional como biólogo, tendo em vista que o licenciado em biologia pode atuar tanto no ensino como na pesquisa. [PF36]

Não posso comentar sobre aspectos mais específicos do curriculo, pois sou pedagoga e trabalho especificamente com estágio. Estabelecemos uma parceria entre Pedagogia e conhecimento específico. Entretanto, posso comentar que ele traz. uma preparação para a atuação docente nos anos finais do fundamental, para atuação no ensino médio e educação profissionalizante, permitindo ao aluno reconhecer-se na docência e no horizonte de possibilidades para atuação profissional. [PP50]

Sobre o Projeto Político de Curso na modalidade de EAD, discutido no quinto episódio ideográfico, como pôde-se constatar em algumas situações, é tido como o documento norteador das ações políticas e pedagógicas, enquanto em outros momentos, não é o único documento e é até desconhecido e desconsiderado pelos professores, como observa-se a seguir:

Procuro seguir as regras, mas sempre quando dá. Gosto de trabalhar do meu jeito, e é isso que não gosto do ensino a distância porque não temos liberdade. É tudo muito 
amarrado, temos que seguir tudo o que o professor formador repassa, acho que dificulta $o$ andamento do curso. [T32]

O PPC não influencia em minha prática pedagógica. Até porque na IES onde atuo eu desconheço este instrumento. Na escola onde leciono no Ensino Fundamental também não o conheço. Minhas práticas são influenciadas através do convivio com outros colegas professores. Observando posturas favoráveis ao ensino e aprendizagem. Além da influencia que tive enquanto aluna, muitas vezes levamos para a sala de aula a metodologia que fomos formados. [T42]

Muitas vezes, o Projeto Politico de Curso é construído a toque de caixa, sem envolver profissionais de todas as áreas ou ainda para atender interesses politico-eleitoreiros. Depois, quando aparecem os problemas, ai são chamadas outras pessoas para ajudar a corrigir os erros. Portanto, há instituições que visam mais interesses pessoais do que institucionais. [PF8, PM8]

No que tange às práticas inovadoras na EAD, pertencentes ao sexto episódio ideográfico, observou-se que as mesmas, na maioria das falas, estão ligadas ao uso das TICs. No geral, as práticas inovadoras destacadas relacionaram-se de modo a romper com a forma tradicional de ensinar e aprender, e com práticas de protagonismo. Por outro lado, vários professores apontaram para a ausência de inovações, com a repetição do fazer presencial na EAD.

Eu tento nas aulas presenciais estabelecer um contrato didatico com os alunos, firmando aliança na metodologia e acompanhamento necessário para a aprendizagem. Uma inovação importante é fazêe-los acreditar que a distancia é ilusória, pois eles podem tornar-se autodidatas e assim são capazes de aprender independente do tipo de modalidade de ensino: a distância ou presencial. [T29]

Isso acontece por meio de envio de novos materiais e midias aos alunos. Essas inovações são feitas pelo acompanhamento dos alunos em esclarecimento de dúvidas através de envio de algum exercício resolvido digitado ou por meio de fotografia da solução feita em papel e caneta. [T47]

Não, infelizmente não pude acrescentar nada de novo. O curso ainda têm algumas falhas como a falta de aulas práticas. Os polos ainda não têm laboratórios e isso dificulta o aprendizado dos alunos. Quando trabalhei uma disciplina de metodologia de ensino, deu-se para trabalhar com algumas pesquisas, senti ali algumas empolgações de ambas as partes. As pesquisas eram locais, percebi os alunos mais motivados. [PF1, T1]

Infelizmente, busco não alterar a proposta do professor. Sigo o que é estabelecido, mesmo que às vezes não veja como sendo o melhor caminho. Sinto que há uma grande dificuldade de interação entre a tutoria, a docência e a coordenação. [T44]

Não vejo inovação alguma. Apenas a publicação da educação tradicional no meio virtual. [T43]. 
No sétimo episódio foi o momento dos sujeitos investigados destacarem, de forma espontânea, outros elementos que pudessem contribuir com a resposta para a interrogação "Que saberes docentes são mobilizados pelos professores dos cursos de Licenciatura em Ciências Naturais e Matemática, desenvolvidos na modalidade de EAD, nos Institutos Federais de Educação, Ciência e Tecnologia?”. Nesse momento, como uma espécie de 'desabafo', surgiram algumas das inquietações e, também, algumas formas otimistas de ver a modalidade de EAD. Eis algumas dessas falas:

O curso a distância tem tido um grande êxito, especialmente no que tange aos alunos que estão realizando o curso. Como participei de turmas no interior de Alagoas, tive o privilégio de ministrar aulas para agricultores, empregados, profissionais liberais, e muitas outras pessoas que pouco tinham como perspectiva um curso superior, mas, este objetivo foi conseguido através desse projeto. Este fato fez com que eu tivesse novos discursos ainda mais enaltecedores da função social do curso a distância, tendo em vista levar a educação para uma maior inclusão social. [PF36].

Os alunos destes cursos estão totalmente despreparados para a realidade de um curso superior e, da maneira como estão sendo formados, servirão somente para nutrir o fraco ensino médio que é praticado no país, sendo cada vez mais necessária a interferência do Estado para suprir a necessidades dos alunos. Penso que uma medida que seja extremamente importante seria a necessidade de um controle de presença, mesmo que virtual, desses alunos, a fim de aferir o tempo que estão se dedicando ao curso. Caso contrário, a realidade de termos que aprovar alunos a fim de servirem de número para não se fecharem cursos e assim minar os recursos continuará sendo uma realidade. [PF6, PP6, T6].

Penso que a EAD precisaria ter mais aulas em vídeo, textos e não deixar que o aluno estude sozinho. Ter mais acompanhamento por parte dos tutores. [T30].

As primeiras disciplinas na $E A D$ são fundamentais. É necessário que o tutor tenha compromisso com a sala de aula conbeça a estrutura da EAD e mantenha contato diariamente com os alunos. [T42].

A quase ausência de formação tecnológica para os professores habilitados. Mesmo a 'X', instituição que tem tradição em EAD em nosso país, continua a formar professores no velho paradigma, sem um currículo que contemple a formação tecnológica necessária para atuação no século XXI. Desta forma, continuamos a formar professores que não são capazes de atuar através das TICs e justificamos dizendo que as redes de ensino ainda não apresentam uma realidade que torne a atuação através das TICs favorável/ indispensável. Com isso, mais uma geração de professores está sendo formada e a dificuldade de atuação através das TICs permanece. Quanto tempo ainda levará para superar o quadro, o gize a fotocópia? [PF4, PP4].

Percebi muita desorganização no instituto do qual trabalhei, houve muita rotatividade do pessoal o que dificultou bastante, talvez seja preciso repensar sobre a rotatividade de 
pessoal, principalmente dos coordenadores. Outro fator desfavorável são as interrupções das bolsas, pois não bá uma continuidade do trabalho quando se encerram as bolsas. Por exemplo: a minha disciplina na matriz estava no $1^{\circ}$ semestre, então, quando terminava eu ficava um tempo distante de tudo até que fosse matriculado outra turma do $1^{\circ}$ semestre. E nesse tempo as coisas mudavam e eu fica desinformado. Nesse caso, o ensino a distância passa a ser apenas um bico para o professor, já que não é possivel viver de apenas três ou cinco bolsas no ano. [PF, T5].

Deveria antes de se ter a conversa com os tutores sobre a sala de aula e o cronograma para determinado AVA poderia ser possivel utilizar outros recursos dentro ou fora deste ambiente, mas como faz parte da sua avaliação como tutor ou como aluno ou formador. Ficamos presos a um único AVA que muitas vezes não satisfaz os atores do processo de ensino e aprendizagem. [T17].

$\mathrm{Na}$ busca pela redução fenomenológica, na análise nomotética, as falas dos sujeitos foram encaminhadas em direção às generalidades, ou seja, ao conteúdo de características básicas compreendidas nas formas de manifestação do fenômeno, passíveis de interpretação. Desse trabalho analítico, as ideias nucleares, observadas a partir das unidades significado que as constituíram, confluíram, cada uma a seu modo, para a elaboração de duas categorias: Saberes Didático-Pedagógicos e Saberes Curriculares. Em um segundo movimento analítico, as duas categorias transformam-se em uma grande categoria aberta: Saberes da Profissionalização Docente.

No que diz respeito à categoria de convergência entre Saberes Didático-Pedagógicos, tomou-se como referência Tardif (2002, p. 36-37), quando afirma que:

[...] é o conjunto de saberes transmitidos pelas instituições de formação de professores. Não se limitam a produzir conhecimentos, mas procuram também incorporá-los à prática do professor [...] esses conhecimentos se transformam em saberes destinados à formação científica ou erudita dos professores, e, caso sejam incorporados à prática docente, esta pode transformar-se em prática científica, em tecnologia de aprendizagem. [...] A articulação entre essas ciências e a prática docente se estabelece concretamente através da formação inicial ou contínua dos professores.

A categoria Saberes Didático-Pedagógicos foi elaborada a partir das seguintes ideias nucleares: (a) formação didático-pedagógica para o exercício da docência; (b) generosidade acadêmica; (c) aliar teoria e prática; (d) cooperação e/ou colaboração; (e) saberes atitudinais; (f) utilizar linguagem adequada; (g) domínio das TICs; (h) Conhecer a EAD; (i) problemas metodológicos; (j) maior experiência do corpo docente; (l) falta de interesse dos estudantes; (m) distanciamento entre professores e estudantes; (n) fragilidades conceituais e técnicas; (o) dificuldade com as TICs; (p) redução do currículo à matriz curricular; (q) currículo desconhecido; (r) currículo obsoleto; (s) o PPC é levado em consideração, mas não é o único elemento norteador; $(\mathrm{t})$ o PPC direciona as ações do curso; ( $\mathrm{u}$ ) o PPC direciona as ações do curso, porém está mal elaborado; (v) desconhecimento do PPC; (x) PPC mal elaborado; (z) 
protagonismo; (aa) não há inovações; (bb) poucas inovações relacionadas com a ruptura, com a forma tradicional de ensinar e aprender; (cc) gestão participativa; (dd) EAD como possibilidade de formação para as classes menos favorecidas; (ee) educação insuficiente para formação de bons profissionais; (ff) a EAD quebra paradigmas.

Ainda no primeiro momento analítico, identificou-se também a categoria Saberes Curriculares que foi constituída pelas ideias nucleares assim delineadas: (a) aliar teoria e prática; (b) cooperação e/ou colaboração; (c) utilizar linguagem adequada; (d) problemas metodológicos; (e) redução do currículo à matriz curricular; (f) currículo percebido para além da matriz curricular; (g) currículo desconhecido; (h) mesmo currículo do curso presencial; (i) o currículo está obsoleto; (j) o PPC é levado em consideração, mas não é o único elemento norteador; (l) o PPC direciona as ações do curso; (m) o PPC direciona as ações do curso, porém está mal elaborado (n) desconhecimento do PPC; (o) PPC mal elaborado; (p) o PPC não é levado em consideração. Considerando essas ideias nucleares que constituem os Saberes Curriculares, toma-se como base o que referencia Tardif (2002, p. 38):

Esses saberes correspondem aos discursos, objetivos, conteúdos e métodos a partir dos quais a instituição escolar categoriza e apresenta os saberes sociais por ela definidos e selecionados como modelos da cultura erudita e de formação para a cultura erudita. Apresentam-se concretamente sob a forma de programas escolares que os professores devem aprender a aplicar.

Por fim, em um segundo movimento analítico de redução, as duas categorias convergiram para uma grande categoria aberta: Saberes da Profissionalização Docente. Os saberes da profissionalização docente são fruto de uma formação inicial e continuada consciente, ética, crítica e pautada em uma trajetória que reflete continuamente sobre o seu processo de formação, sobre o seu espaço de trabalho e sobre a mundo que deseja para si e para os outros.

\section{Movimentos dos saberes da formação docente: caminhando para uma síntese}

O movimento realizado durante as análises ideográfica e nomotética desvelou articulações que construíram a categoria aberta Saberes da Profissionalização Docente. Essa categoria revela as faces do fenômeno saberes-dos-professores-das-Ciências-da-Natureza-e-Matemática-das-Licenciaturas-em-EAD-nos-IF, visualizadas e compreendidas no contexto dos cursos de Licenciatura em Ciências Naturais e Matemática ofertados na modalidade de EAD, pelos IF.

No decorrer da pesquisa de campo, o fenômeno foi tratado de forma a trazer à luz os saberes docentes mobilizados pelos professores, as possibilidades sinalizadas por esses saberes e os tensionamentos apontados. $\mathrm{E}$ foi nesse entremeio que se identificaram várias contradições entre o que se escreve, o que se diz e o que se faz.

$\mathrm{Na}$ análise ideográfica, sobressaiu a fragilidade teórica no que tange às diferenças entre a modalidade presencial e a modalidade a distância. Há pouca integração entre os sujeitos investigados, sendo que, principalmente, os tutores acreditam que os cursos poderiam ser melhores 
se esta interação acontecesse. A fala de um professor pesquisador que não conhece o Projeto Pedagógico do Curso vai ao encontro das angústias dos tutores. Os tutores, sujeitos que estão na ponta do processo de ensino-aprendizagem, em contato direto com os estudantes, aparecem como o elo mais fragilizado, pois a maioria não tem vínculo com a instituição ofertante do curso, sua remuneração é através de bolsas de estudo (as de menor valor), já que as de maior valor estão, também, com os professores com vínculo na instituição ofertante. Também são os tutores os profissionais com menor titulação acadêmica, embora alguns possuam título de Mestre.

Para a compreensão do fenômeno, foi necessário estabelecer relações com os objetivos originários da pesquisa, como "analisar os mapas ilustrativos que determinaram a implantação dos cursos de Licenciatura na modalidade de EAD”. Sobre este aspecto, pode-se afirmar que todos os documentos analisados contribuíram, de alguma forma, para que a elucidação do problema fosse alcançada, especialmente no que tange à identificação de que a escrita documental foge da efetiva prática diária nos cursos investigados. A EAD, nos ordenamentos institucionais, é apresentada de forma rápida e aparentemente para cumprir a orientação legal de sua necessidade. Os Projetos Políticos de Curso apresentam-se em consonância com a legislação vigente, mas não agregam elementos capazes de dar conta da diversidade oriunda da modalidade de EAD. São, em sua maioria, réplicas dos documentos de criação dos mesmos cursos oferecidos na modalidade presencial. Pôde-se observar, também, a partir do confronto entre as falas dos sujeitos investigados e dos documentos institucionais, o distanciamento entre o que se planeja e o que se realiza.

Quanto a "analisar o modelo adotado para a formação de professores dos cursos de Licenciatura na modalidade de EAD" e "identificar os desenhos curriculares dos cursos investigados" observou-se, considerando os ordenamentos institucionais analisados e também as falas dos sujeitos investigados, que boa parte ainda tem como referência para formação os cursos presenciais. E, como tal, carregam para os cursos a distância todos os problemas dos cursos presenciais, além de agregar novos problemas gerados pela distância física e pelo desconhecimento das características próprias dessa modalidade de educação. Por outro lado, aparece de forma clara o interesse que muitos professores e principalmente tutores têm em capacitarse para melhorar sua ação docente e atender de forma mais adequada às demandas oriundas da EAD. A capacitação aparece em forma de ações isoladas e descontinuadas. Há várias falas, especialmente de tutores, que se encontram desgostosos por não haver mais capacitações e por se sentirem isolados no processo de ensino-aprendizagem. Apenas um IF afirma que, após ter sido avaliado pelo MEC, reformulou seu Projeto Pedagógico do Curso, a fim de rever o curso que oferecia. O gestor afirmou que vinha observando as fragilidades do curso, mas que somente depois da "visita dos avaliadores do MEC" é que se deu a mudança.

Sobre os 'tensionamentos do trabalho docente diante dos saberes mobilizados', o que se apresenta com maior força são os problemas metodológicos oriundos do desconhecimento das possibilidades da modalidade de EAD (reflexo da falta de formação, destacada anteriormente). Também se percebe o ranço sentido pelos sujeitos que trabalham com a EAD no que tange à desvalorização da modalidade, quando comparada com o mesmo curso ofertado de forma presencial. Outros tensionamentos são semelhantes aos da educação presencial, como a dificuldade no trato com as tecnologias, o desinteresse dos estudantes e falta de metodologia dos docentes. 
Compreendeu-se, então, que os saberes docentes relacionam-se necessariamente à profissionalização docente. A profissão docente não é neutra, como afirma Cunha (2005), e, se não neutra, precisa estar munida de conceitos e práticas voltados para a formação de um sujeito capaz de interagir e transformar um mundo de ideologias e valores conflitantes.

A formação acadêmica Lato e Stricto Sensu dos professores é tão necessária quanto o desenvolvimento de saberes da formação profissional: os saberes disciplinares, os saberes curriculares, os saberes pré-profissionais e os saberes experienciais (TARDIF, 2002). Os saberes docentes não estão prontos e acabados, estão em constante movimento e precisam sempre ser mobilizados, considerando-se a complexidade das situações profissionais nas quais o professor se envolve. Nesse viés, os saberes docentes nunca estão consolidados, pois cada grupo, cada tempo e cada espaço da sala de aula requer uma intervenção diferenciada desses saberes.

Entender que as inovações pedagógicas também fazem parte da profissionalização docente é dar espaço ao novo sem, necessariamente, desfazer-se do antigo. É olhar, para o que se tem, com olhos capazes de ver possibilidades de aprendizagens em lugares onde antes pouca coisa se podia enxergar. Ressignificar, protagonizar, reconfigurar, participar, mediar, romper, gestar são algumas formas de inovar e, dessa forma, inovar pedagogicamente.

Ao final, defende-se, a partir da análise ideográfica e nomotética, a importância de que os saberes docentes são oriundos da profissionalização docente, fruto de uma formação inicial e continuada consciente, ética, crítica e pautada em uma trajetória que reflita continuamente sobre o seu processo de formação, sobre o seu espaço de trabalho e sobre a mundo que deseja para si e para os outros.

\section{Referências}

BICUDO, M. A. V. A contribuição da fenomenologia à educação. In: BICUDO. M. A. V.; CAPPELLETTI, I. F. (Org.). Fenomenologia: uma visão abrangente da educação. São Paulo: Olho d'Água, 1999. p. 11-51.

BRASIL. Lei no 9.394, de 20 de dezembro de 1996. Estabelece as diretrizes e bases da educação nacional. Diário Oficial da União, Brasília, 23 dez. 1996. Disponível em: <http:/ /www.planalto.gov.br/ccivil_03/Leis/L9394.htm>. Acesso em: 04 jan. 2016.

. Lei no 11.892 , de 29 de dezembro de 2008. Institui a rede federal de educação profissional, científica e tecnológica, cria os institutos federais de educação, ciência e tecnologia e dá outras providências. Diário Oficial da União, Brasília, 30 dez. 2008. Disponível em: <http://www.planalto.gov.br/ccivil_03/_ato2007-2010/2008/lei/111892. htm>. Acesso em: 23 mar. 2011.

CHARLOT, B. Da relação com o saber. Porto Alegre: Artes Médicas, 2000.

CONTRERAS, J. A autonomia de professores. São Paulo: Cortez, 2002.

CUNHA, M. I. O professor universitário na transição de paradigmas. São Paulo: JM Editora, 2005. 
FREIRE, P. Pedagogia da autonomia: saberes necessários à prática educativa. 9. ed. Rio de Janeiro: Paz e Terra, 1996.

GOLDENBERG, M. A arte de pesquisar: como fazer pesquisa qualitativa em ciências sociais. Rio de Janeiro: Record, 1997.

LAPLANTINE, F. Aprender antropologia. São Paulo: Brasiliense, 2006.

NÓVOA, A. O professor pesquisador e reflexivo. [Entrevista concedida ao Programa Salto para o Futuro, TV Escola em 2001]. Disponível em: < http:/ / tvescola.mec.gov.br/tve/ serie/salto/entrevista/antonio-novoa>. Acesso em: 18 mar. 2016.

PACHECO, E. Os institutos federais: uma revolução na educação profissional e tecnológica. Brasília: Ministério da Educação, [2010]. Disponível em: <http://portal.mec.gov. $\mathrm{br} / \mathrm{setec} /$ arquivos/pdf/insti_evolucao.pdf>. Acesso em: 23 mar. 2013.

PIMENTA, S. G. (Org.). Saberes pedagógicos e atividade docente. São Paulo: Cortez, 1999.

TARDIF, M. Saberes docentes e formação profissional. Petrópolis: Vozes, 2002.

VASCONCELLOS, C. Construção do conhecimento em sala de aula. São Paulo: Libertad, 2002. 